\title{
Women's experiences of using a Snoezelen room during labour in West Australia
}

\section{Summary}

Objective: The purpose of this study was to explore women's experience of using a Snoezelen room during their labour.

Design: A qualitative exploratory design was conducted to provide insight to the phenomenon of using a Snoezelen room for labouring women and identify factors that could facilitate or inhibit use of this environment. The constant comparison method modified from the grounded theory methodology was used to analyse data from indepth interviews.

Setting: Osborne Park Hospital (OPH), the second largest public provider of obstetric services in West Australia, was the study setting.

Participants: Sixteen women, recruited from July 2005 to June 2006, agreed to participate in an in-depth interview and share their experience of using the Snoezelen room during a recent labour.

Findings: Six themes were extracted from the data providing insight to what a Snoezelen environment can offer a labouring woman: Distraction; Relaxation; Comfort; Environmental Control; Choice of Complementary Therapies; and Safety in a Homelike Atmosphere. Additional categories revealed factors that facilitated and/or detracted use of the room such as familiarity with features, being offered information and choice, timing in labour, the support person's response and working order of the room's features.

Implications for practice: When sharing their experience, women focused upon the process of their labour and how they managed this process rather than specific outcomes such as analgesic used or type of birth. Although outcomes such as type of birth may not have been their preferred choice, these women were able to achieve satisfaction with how they managed their labour while in the Snoezelen room. This midwifery-led initiative contributed to these women's labour experiences, by offering a combination of complementary therapies within the safety of a hospital environment.

Key words: Snoezelen, childbirth, labour 


\section{Introduction}

Snoezelen is a concept whereby an indoor environment is created to provide comfort using controllable stimuli. Specially designed rooms expose the user to multiple sensory stimulations combining vision, touch, sounds, and aromas. These rooms are credited with providing therapeutic or educational effects and positive emotions such as wellbeing, rest, satisfaction, poise and joy (International Snoezelen Association nd). The original purpose of the Snoezelen concept was as a leisure activity for the mentally impaired.

Use of Snoezelen environments has been described for adults with psychiatric disorders (Costa et al 2006); multiple handicap clients (Ashby et al 1995, Lancioni et al 2005); nursing home and psychogeriatric clients (van Diepen et al 2002, van Weert et al 2004); palliative day-care clients (Schofield \& Payne 2003); and end-stage Alzheimer's clients (Chitsey et al 2002). The concept has also been used for relaxation for neonates (Aspin 2004); critically ill children (White 1997); and chronic pain sufferers (Schofield 1996, 2002, Schofield et al 1998). Many studies focused specifically on dementia clients (Pinkney 1997, van Diepen et al 2002, Baker et al 2003, Cornell 2004, Cox et al 2004, Dalferth 2004, Baillon et al 2004, Verkaik et al 2005). Further research is recommended to explore the impact of these environments within different contexts (Chung \& Lai 2004).

The use of strategies to enhance relaxation in pregnant and labouring women is not a new concept within midwifery. Use of complementary therapies by midwives to enhance relaxation in pregnant women with psychological stress has been increasing (Tiran \& Chummun 2004). Interventions to promote relaxation and assist with pain management in labouring women include strategies such as immersion in water, acupuncture, acupressure, massage, and transcutaneous electrical nerve stimulation (TENS). These complementary strategies can be used together with conventional pain relieving measures such as analgesia, epidural anaesthesia and nitrous oxide. Water immersion in early labour has been found to reduce maternal pain and analgesia use without producing adverse outcomes on length of labour or type of birth (Cluett et al 2004). Acupuncture has also been reported to reduce the need for analgesics for labouring women (White 2003), however, evidence to support TENS is still inconclusive. Although, most women who use TENS indicate they would use it again, their use of additional analgesics during labour makes it difficult to determine whether analgesic effects were due to TENS alone (Johnson 1997, 2001).

There is no research to date that examines any therapeutic effects in the use of Snoezelen environments with pregnant or labouring women. Given the growing popularity of the Snoezelen concept as a means to enhance relaxation, it is timely that the experience of using such an environment for childbearing women be explored. Accordingly, the purpose of this study was to explore women's experience of using a Snoezelen room during their labour.

\section{Methods}

Osborne Park Hospital (OPH) was the setting for this study and is the second largest public provider of obstetric services in West Australia. The maternity setting has on 
average 1500 births per year. Women qualify to birth at OPH after they have reached 35 completed weeks gestation. This facility does not accept high-risk women such as insulin dependent diabetics, women who are over $125 \mathrm{~kg}$, or women with severe preeclampsia as it does not have a neonatal nursery or access to 24 hour on-site medical consultants. Pharmacological options available to women include intramuscular narcotic administration, epidural anaesthesia, and nitrous oxide. Alternative nonpharmacological options include a spa, fit balls, TENS, beanbags, use of hot packs and CD players in each birth suite.

The Snoezelen room was a midwifery-led initiative specifically designed for maternity clients (Figure 1 and 2). It has polished floorboards and soft earthy colours of green, brown, terracotta and yellow. These colours were chosen for their link with birth and nature. The walls are a soft green colour. The room provides a three-seater lounge with a chaise and a chair with a wrap-around backrest. There is a large soft rug and threesquare ottomans. The main features of the room are the wheel projection that rotates to display wall patterns and fibre optic lights that slowly change colours. A fish tank with colourful tropical fish, relaxation music with a CD player and aromatherapy of the client's choice compliments the ambience of the room.

A qualitative exploratory design was used as the phenomenon of using the Snoezelen room with labouring clients has not been reported previously. Qualitative research is ideally suited to answering the question "what is this phenomenon?" and revealing how a phenomenon is manifested plus its underlying processes (Polit \& Beck, 2006).

A purposive sample of women was recruited from July 2005 to June 2006. Women were made aware of the Snoezelen room during antenatal classes. An information letter and invitation to participate was offered during the classes. Twenty-three pregnant women expressed interest antenatally in using the Sneozelen room with nine women being interviewed. The remaining fourteen women did not use the room and issues such as forgetting to ask, it not being suggested by their midwife or having an early epidural, an induction or an elective caesarean birth were some of the reasons offered. To access women, who did not attend antenatal classes, a book was put in the assessment area and midwives were asked to enter names and dates when a woman used the room during her labour. An information letter and invitation to participate was given to these women postnatally by the researcher to avoid the perception of coercion if clinical midwives approached them. Interested women placed the expression of interest note in a locked box at the reception area or posted it to the researcher. Twelve women were approached using this strategy with seven confirming their interest to be interviewed. Data collection continued until data saturation was reached. A total of 16 women were interviewed.

The researcher contacted the women 5 to 6 weeks after their birth to allow time for recuperation but also not to introduce recall bias by waiting too long after the event. Arrangements were made to conduct an interview in the comfort and privacy of their home. The first author conducted the interviews, as she is a midwife but not directly involved in patient care at the hospital. The interviewer in qualitative research is considered a data-collecting instrument and therefore their education and experience are important to establish credibility (Polit \& Beck 2006). Being a midwife with experience 
in conducting qualitative interviews was an asset. In addition, being an objective nonclinical person with no vested interest in the Snoezelen room was essential, as women felt comfortable to openly share both positive and negative aspects of their labour experience.

Participants signed the consent form at the beginning of the interview after the study purpose was reiterated. An interview guide with open-ended questions was used to encourage sharing of their experience. The interview began by asking the participant to "tell the story of their labour" which incorporated use of the Snoezelen room but also clarified its use in the context of the entire labour experience. Additional prompting questions such as: "How did you use the room, What did you like or not like about the room, Would you use the room again in future labours and Would you recommend the room to other women" were used. Demographic details such as age, parity, and type of birth were collected to provide a participant profile. All interviews were audio-recorded and transcribed verbatim.

The constant comparison method modified from the grounded theory methodology was used to analyse the transcripts (Strauss \& Corbin 1998). Categories obtained from the data were constantly compared with earlier data so similarities and differences could be determined. Emerging concepts were labelled and formed the basis for a categorisation scheme. Data were then reviewed and coded based on the identified categories (Polit \& Beck 2006). Initially, the research team reviewed and analysed the transcripts separately to avoid introducing bias. Tentative categories were then presented and discussed during team meetings. Midwives not involved in the study acted as external reviewers ensuring dependability of the analysis. Refinement of themes and their definitions was reached by consensus. Member checks were then carried out with four participants who confirmed the categories. The first author maintained a decision trail during the data analysis process to enhance auditability.

The university and participating hospital's ethics committees approved this research. Data were coded by a number to ensure confidentiality. Transcripts and demographic forms were stored in a locked cabinet at the university with researcher access only. The person who transcribed the interviews signed a confidentiality agreement to ensure they wound not breach confidentiality.

\section{Findings}

Sixteen women who had used the Snoezelen room during a recent labour were interviewed. All participants indicated they would use the room in a future labour and recommend it for other labouring women. Fourteen women were primiparas and two were multiparas. Maternal age ranged from 19 to 36 years (mean 27.6). Fourteen women were living with a partner, one lived with her partner and extended family and one was a single parent. All women spoke English and four also spoke another language. Demographic data is provided in Table 1. Time in the Snoezelen room varied with four women staying from 20 to 40 minutes, seven women staying between 1 to 2 hours, and five women staying between 3 and 8 hours. The mean time in the room was 2 hours and the mode was 1 hour. 
Six key themes emerged highlighting what the Snoezelen environment could offer a labouring woman: Distraction, Relaxation, Comfort, Environmental control, Choice of complementary therapies and Safety in a non-clinical atmosphere (Figure 3). Factors were also identified that facilitated or inhibited women being able to achieve all that could be offered by the Snoezelen room (Box 1). Supporting quotes will be provided in italic to illustrate the key themes and experiences will be distinguished from the 16 participants as P1 to P16.

\section{Distraction}

Participants revealed how they used the variety of complementary therapies for distraction. Participants shared how they were able to be mentally and/or physically amused. The Fiber Optics were there and in between contraction I was like 'oh wow that's pretty cool', I'll put them around me so I had them over my belly, the contraction are like a wave and the colours were like a wave (P2). Having choice in features allowed women to find what they liked and while doing so, these activities occupied time. Some women enjoyed having all the features working as it gave them a focus beyond their own physical situation. I think all of them together because it was such a distraction you're far more focused on what was going on in the room rather than how you're feeling (P10)

\section{Relaxation}

The second theme that emerged revealed how the Snoezelen environment was useful in promoting relaxation. The Snoezelen room just helped me to just relax a little more. I think it just helps calm the nerves a little bit (P8). The distractions assisted some women to focus, which resulted in them achieving a more relaxed state. Snoezelen room gave more relaxation wise, because there were other things around you and while the contractions are there you try and focus on something else within that room (P6). Some women attributed a particular feature to enhancing relaxation. The fish were so peaceful, just like blobbing along like nothing was wrong, it kind of mesmerized me a bit cause I wasn't relaxed and looking at something so relaxed helped me to relax (P5). A number of women commented that they had fish tanks at home or enjoyed watching fish. Others liked the fish tank but used it in collaboration with other features. The fish tank and there was kind of like coloured lights on the wall as well, they were on, and there was a disco light as well. It was very, very calming (P10).

\section{Comfort}

Comfort was the third theme. Having an assortment of furniture such as a sofa and the square ottomans facilitated relaxation and comfort, as participants were able to modify the room's features, as they would do in their own home. I almost felt like I was laying on my own lounge room just relaxing (P7). Being in a room with a hospital bed does not allow for the flexibility of movement afforded to these labouring women. The fact that there was moveable furniture there that we could play around with in terms of helping me relax (P14). Interestingly flexibly in movement was noted even though the Snoezelen room is physically not bigger than a single patient room. There was different ways you could sit rather than being stuck over a hospital bed, you could sit all different 
ways like you'd be at home (P3). The prominence of the bed in the traditional hospital room was seen as something that impeded freedom of movement. You didn't have the big bed in the middle of the room, there were stools that you could sit on and there was a couch, there was carpet on the floor (P14). Other items that were not usually in the room could also be brought in such as a fit ball or beanbag. Leaning over the footstool was really, really comfortable, I think I had a fit ball in there as well (P10). Finally, the privacy of the room was noted as reassuring should the woman feel inhibited from making noise. I could just be myself and grunt and not worry that I was too loud, you felt more comfortable, sort of enclosed (P13).

\section{Environmental control}

Environmental control was noted as another important theme. Participants valued the opportunity to capture control where possible during the labour. The features in the Snoezelen environment could be manipulated to suit women's preferences. You could control how light or how dark you wanted it, or I should say I barked orders at people to get them to do it to how I wanted it (P2). Most of the labouring women did not alter the features but relied on their partner, support person and/or the midwife to do this. Lights could be turned up or dimmed, specific features like the fibro-optics lights could be turned on, wrapped around the women or simply left in the corner of the room. This hospital setting also has a spa for labouring women and more than half of the participants choose to use the spa during their labour either before or after using the room. Everything was how I pictured it, using the Snoezelen room, using the spa, walking, being active, very quiet, like I was just in a trance, I was so in control of my own body that it felt really empowering (P14).

Respect for privacy was noted as being different by clinical staff when in the Snoezelen room. Staff knocked on the door more than in the assessment area or birth suite. The privacy, only two people were able to use it at a time, the midwives actually tell you when their next visit will be so that's one good point about it (P8). The Snoezelen room had no windows and when the door was closed a sign was posted outside to make people aware that it was in use. The room was also more sound proof than the tradition hospital room. When the midwives wanted to enter they knocked on the door, there wasn't anyone just bursting in whenever they wanted to, I couldn't hear anything else going on outside so we were very much alone (P9). The usual traffic of clinicians freely moving in and out of the labouring woman's room changed in the Snoezelen room. This change was highlighted when the woman was then moved to the birth suite closer to giving birth. Just annoying having people intrude on your space when you're going through this, I found that quite upsetting really that people were just wandering in and out and you didn't really have any privacy $(\mathrm{P} 12)$.

\section{Choice of complementary therapies}

Having access and choice to a range of complementary therapies was also noted as important. Some women tried all the features when they first arrived in the room. We used the Optic Fiber lights and the fish tank. We had the music going and the projector one, the one that looks like bubbles on the wall, we were pretty much looking at all of those and the blocks, the square blocks were really good to lean over (P3). Some 
women had been using particular relaxation strategies at home such as listening to a particular CD, using self-hypnosis or aromatherapy and were then able to continue using these strategies in the Snoezelen room. I had my own essentials oils so we put those on in the room, lavender. It was a relaxation $C D$ that they had in there which was quite nice, cause I had my own relaxation CDs with me as well (P10). Not every woman wanted all of the features and they were able to adjust or switch off any features that were not desirable and focus on what worked for them. They had the ottoman thing that I was using to squeeze unto and also to rock myself back and forth which was great, I don't remember hearing much of the music (P9).

\section{Safety in a non-clinical atmosphere}

Although this cohort of women chose to have a hospital birth, many indicated how they appreciated knowing they had the safety of having medical resources nearby but were able to "escape" from the hospital environment, abeit temporarily by being in the Snoezelen room. Escape from the hospital environment, which is associated with labour and pain and needles, and doctors and horrible things, they're doing their job I know, but at the time you just think you want to get away from it (P5). Some women wanted a medical setting as it represented safety. I actually really appreciate a medical surround, I was giving birth in a hospital suite but I was just going to be in this room for a little while (P11). Other participants, who felt hospital was their preferred place to birth, did not necessarily enjoy the sterile environment. You know how hospitals are so white and sterile sometimes it was nice actually getting a break from that (P9). The Snoezelen room offered a quiet and private retreat from the assessment area or birth suite and these women appreciated having this haven. You couldn't hear trolleys or nurses yelling so it was nice and insulated and it was really comfortable and you did feel safe because there was someone out the door (P13). Only one woman indicated she would have liked to birth in the Snoezelen room but most women were happy to move to the birth suite as that was seen to be more ideal for that event.

Five factors were noted as being important in facilitating or inhibiting use of the room. These were Familiarity with features, Information and choice, Timing in labour, Support person's response and the Working order of the room's features.

\section{Familiarity with features}

If a woman or her partner were familiar with the features of the Snoezelen room, they were better able to tailor the room to meet changing needs. In the majority of situations, it was the support person who adjusted the features of the room upon requests by the labouring woman. The midwives facilitated the support person's ability to modify the features by orientating the couple when originally placed in the room. The midwife turned everything on and told us both how to use it all so he [partner] just took the role of making sure the music was playing, the lights were what I felt comfortable with, propping pillows up, laying the Fiber Optics over how I wanted them to be laid over (P6). As labour progressed partners or support people were able to modify features. The lavender was really strong, they put a lot of it on so I got my mum to turn that off (P2). Not every woman wanted every feature on due to personal preferences. We used the lights, the aromatherapy as well, I found that really relaxing, I used those [fibro-optic lights] but I didn't find them beneficial, others may have, but I didn't (P8). If a couple 
were not familiar or had forgotten how to adjust the features of the Snoezelen room it made it more difficult to customise the room to suit their needs. [Midwife] just kind of turned everything on and left us to it. We didn't know how to turn things on or off or do anything with any of it, had we been able to actually play around with it, it might have made the experience a little bit different (P1).

\section{Information and choice}

Being given information regarding options gave the women choice in selecting resources if and when they wanted them. I felt that I used everything that was available to me and felt comfortable with it all, used them in the order that I wanted to, because I did want to have baby as naturally as possible (P6). A small number of women expressed disappointment in not being able to use all the resources available to them such as the spa, Snoezelen room or fit ball until they remembered to ask. I found the midwives weren't really that pro active in coming out and saying 'we've got this, this and this on offer and I can bring them all to you and you can try them out and see which one works for you', which would have been better (P1). This placed an extra burden on the woman to remember and ask for what she wanted in addition to coping with labour. Women indicated they wanted to be presented with information and options so they could make an informed choice regarding what to try and when. I don't think we were remembering anything except that I was getting contractions and we were going to have a baby, so it was really good that the midwives came in and offered, because we wouldn't have remembered (P14).

\section{Timing in labour}

Many of the participants used the Snoezelen room during early labour. However, there were a few women who were in the room for extended periods and did not leave the room until they felt an urge to push. Women who were comfortable with the room and able to adapt the features were pleased to stay. The Snoezelen room in this maternity setting was not planned for actual births and consequently, women are transferred to birth suite to have their baby. The appropriateness of timing in labour was dependent upon when the women entered the room and how comfortable she was adapting the room. I think that the room should be used before you're at the point where you can't enjoy it or before none of the things appeal to your senses because you're in so much pain (P5). In contrast, another woman found the room particularly useful in more active labour when the contractions were stronger. We were in there when it was really bad, it was quite good cause it was dark and I was really appreciative of that cause you couldn't focus on things anyway, so it was nice that it was dark and it was quite good along with the gas (P13). Some participants used other methods of pain relief such as TENS, nitrous oxide or pethidine while in the room. A few chose to have an epidural and did not remain in the room once that decision was made.

There is no particular time in labour when the room shouldn't be used. The issue was the couple's familiarity and comfort with the room. A woman who has been eased into using the room since early labour may wish to stay to the later stages as she adjusts the features. However, putting a woman into the room during active labour, when she hasn't had time to become familiar with the room is not recommended. For example, one woman entered the room in active labour after being given Pethidine without 
instruction on how to adapt the features. She described her experience as: really cold and harsh and unforgiving and just way too much, way too much stimulation (P1).

\section{Support person's response}

The reaction of the support person to the Snoezelen room influenced how long the woman stayed in the room. Positive perceptions from the support person reinforced the woman's decision to remain in the room. It makes it more comfortable for the people who are with you to support you in labour, they found it a lot more comfortable than sitting in a hospital room (P3). Partners also shared in the relaxation. My husband fell asleep in the corner, which he liked (P6). Although this type of relaxation was desirable for some couples, another father was worried that falling asleep meant he wasn't being as supportive as he wished and so they kept their stay short. Many partners appreciated the distraction and comfort in this safe non-clinical environment. He thought it was pretty trippy, he thought it was quite nice, walking around, he was in and out of the room phoning people and stuff (P7). Having a relaxed partner had a positive effect on women who were then able to focus on their labour without worrying about an anxious partner. He was quite comfortable and it's sort of a fun room to be in. He read the paper, and that was good for me because with the first labour he was so attentive and stressful and I really wanted him to be calm and relaxed and have a lot of energy for when I really needed him (P11). Only one partner was uncomfortable in the room due to the room having no windows and the woman subsequently kept her stay short. It got a bit claustrophobic, we needed some fresh air, so we got out of there (P4).

\section{Working order of the room's features}

When the couple were comfortable and familiar with the room's features and they worked, they were more willing to try everything and modify the room as needed. They're pretty much got everything, they're got the music, got the incense, I had the lavender incense burning, the fish, the music, the mirror ball, the Fiber optic lights, had comfortable chairs (P7). Most women were satisfied with the room and how they were able to cope with their labour while in the room. I was doing quite well, achieved all my goals, I think that the Snoezelen room definitely did help (P8). If expectations could be met then the women rarely indicated they would change how they used the room. I'd probably do everything the exact same way again, because I pretty much did the things that I knew were better for me and my body first (P6). However, expectations were not met for one woman who was not offered the room and then asked to use it when she remembered. She was getting distressed with contractions, had recently been given Pethidine and received no instructions regarding using the room. In addition, some of the features were not in working order. Although, disappointed, she said she would definitely try the room again and felt that if everything worked the experience would be been worthwhile.

\section{Discussion}

The phenomenon of using the Snoezelen environment for maternity clients was new and innovative warranting use of a qualitative approach. Findings are presented with rich 
description to allow the reader to determine the transferability of this phenomenon to other contexts beyond this West Australian example (Polit \& Beck 2006).

Relaxation was a common theme reported by women using the Snoezelen room. Relaxation was an anticipated effect of the Snoezelen environment given its original purpose. Relaxation has been a outcome for dementia patients, chronic pain sufferers, palliative clients, and mentally handicap clients (Schofield 1996, 2002, Schofield et al 1998; Baker et al 2003, Baillon et al 2004, Cornell 2004, Cox et al 2004, Dalferth 2004, Lancioni et al 2005, van Weert et al 2004, Verkaik et al 2005). Clients are not the only people who benefit from using the environment as revealed in a Canadian study with psychiatric clients and hospital employees. Participation in a 20-minute session had positive physiological effects for both groups who all felt more passive, relaxed, cheerful, focused, optimistic, calm and comfortable (Reddon et al 2004).

Complementary therapies are viewed as relaxation strategies but relaxation also increases endorphin release, which enhances the capacity to cope with pain (Tiran \& Chummun 2004). Being in a more relaxed state contributes to normalising childbirth and increasing maternal satisfaction (Mousley 2005). Aromatherapy is particularly conducive to reducing anxiety and fear during labour (Burns et al 2000), thereby creating relaxation and normality (Nanayakkara 2001). Anxiety has been related to fear of pain, fear of loss of control, safety, noise and unfamiliarity with the environment (Koehn 2000). Few complementary therapies have undergone rigorous scientific study (Smith et al 2003) in relation to their impact on pain management. Given the subjective nature of pain relief and the ethical difficulties in conducting random control trials with such interventions, it may be more appropriate to focus upon alterative evidence. Recent trends toward acceptance of qualitative methods in nursing and midwifery are being suggested with complementary therapy research (Biley \& Freshwater 1999).

Participants in this study appreciated the flexibility in being able to move freely. Many women find it very unhelpful to be confined to a bed during their labour (Findley \& Chamberlain 1999). Freedom of movement is a major component of pain management and women use movement to make their labour more comfortable (Shilling et al 2004). Traditional maternity assessment areas are often similar to hospital rooms, dominated by a bed, which make unrestricted movement problematical.

All participants used music at some time during their stay in the Snoezelen room. The majority of women listened to the music provided, although a few did bring their own CDs. A combination of music and support has been found to be a helpful coping strategy during labour (Browning 2000). Post-operative clients have also found music to provide comfort, familiarity in an unknown environment and a distraction from fear, pain and anxiety (McCaffrey 2000; Dunn 2004).

Although complementary therapies tend to be viewed in relation to a non-medicated labour (Nanayakkara 2001), the women in this study chose to have a hospital birth. A small number of participants indicated a preference not to use pharmacological pain relieving measures. However, the majority of women indicated they were happy to consider using options depending upon their labour progress. Evidence indicates that women choosing a hospital birth due to risk and safety issues described their birth experience in terms of their surroundings and issues of privacy, high technology and 
comfort (Ogden et al 1998). The women who used the Snoezelen room enjoyed the temporary escape in a non-clinical environment but appreciated that remaining in hospital afforded them the safety and resources they desired.

All participants indicated they would use the Snoezelen room for future labours. Women's stories focused upon the process of labour and how they managed this process rather than specific outcomes such as analgesic or type of birth. Although a few felt disappointment with outcomes such as a forceps or caesarean birth, most were satisfied with how they were able to manage labour while in the Snoezelen room. The findings support the conclusions offered regarding non-pharmacological choices to pain relief (Simkin \& Bolding 2004). Approaches can be combined safely or used sequentially to increase effect plus used instead of or as an adjunct to pain relief medications. As well as being inexpensive and relatively easy to use, non-pharmacological choices rate highly in terms of women's satisfaction and desire for use in future labours (Simkin \& Bolding 2004). Women have indicated that support, information, intervention, decision making, control and pain relief contribute to a positive birth experience (Lavender et al 1999). The importance of making women aware of options and then supporting their decisions is reinforced in this study where participants indicated how information and choice facilitated use of the Snoezelen room.

Some complementary therapies, such as massage, reflexology, acupuncture, or therapeutic touch, require specific training. Not all midwives have the time or interest to provide these specialised services. The challenge of providing accessible, cost effective complementary services involves ensuring client access to therapies often considered a "luxury" (Tiran 2003). The therapies chosen for the Snoezelen room used in this study such as specialised lighting, music, aromatherapy, flexible furniture and the fish tank required minimal education for staff and focused on enhancing client autonomy and control.

\section{Conclusion}

This study demonstrates how a midwifery-led initiative contributed to the labour experiences of a cohort of West Australian women by offering a combination of complementary therapies within the safety of a hospital environment. The Snoezelen room also provided environmental control, relaxation, comfort and distraction. Adoption of the Snoezelen concept for these maternity clients' highlights a unique example of forward thinking midwives using an innovative opportunity to advocate for childbearing women. 


\section{References}

Ashby M, Lindsay W, Pitcaithly D et al 1995 Snoezelen: Its effects on concentration and responsiveness in people with profound multiple handicaps. British Journal of Occupational Therapy 58: 303-7.

Aspin A 2004 The concept of Snoezelen: Sensory stimulation and relaxation for neonates. Journal of Neonatal Nursing 10: 47-51.

Baillon S, van Diepen E, Prettyman R et al 2004 A comparison of the effects of Snoezelen and reminiscence therapy on the agitated behaviour of patients with dementia. International Journal of Geriatric Psychiatry 19: 1047-1052.

Baker R, Holloway J, Holtkamp C et al 2003 Effects of multi-sensory stimulation for people with dementia. Journal of Advanced Nursing 43: 465-477.

Biley F, Freshwater D 1999 Trends in nursing and midwifery research and the need for change in complementary therapy research. Complementary Therapies in Nursing and Research 5: 99-102.

Browning C 2000 Using music during childbirth. Birth 27: 272-276.

Burns E, Blamey C, Ersser J et al 2000 The use of aromatherapy in intrapartum midwifery practice an observational study. Complementary Therapies in Nursing and Midwifery 6: 33-34.

Chitsey A, Haight B, Jones M 2002 Snoezelen: A multisensory environmental intervention. Journal of Gerontological Nursing 28: 41-9.

Chung J, Lai C 2004 Snoezelen for dementia. The Cochrane Library (Oxford). 4: ID\#CD003152.

Cluett E, Nikodem V, McCandlish R et al 2004 Immersion In water in pregnancy, labour and birth. The Cochrane Library, Oxford. 4: ID \#/CD000111.

Cornell A 2004 Evaluating the effectiveness of Snoezelen on women who have a dementing illness. International Journal of Psychiatric Nursing Research 9: 1045-62.

Costa D, Morra J, Solomon D et al 2006 Snoezelen and sensory-based treatment for adults with psychiatric disorders. Occupational Therapy Practice 11:19-23.

Cox H, Burns I, Savage S 2004 Multisensory environments for leisure: Promoting wellbeing in nursing home residents with dementia. Journal of Gerontological Nursing 30: 37-45.

Dalferth M 2004 Snoezelen in nursing homes: The results of a scientific study in the BRK nursing home in Regensburg. Ergotherapie Rehabil 43: 20-32.

Dunn K 2004 Music and the reduction of post-operative pain. Nursing Standard 18: 3339.

Findley I, Chamberlain G 1999 ABC of labour care: relief of pain. British Medical Journal 318: 927-930.

International Snoezelen Association, no date Sensory stimulation and relaxation in special interior rooms. Retrieved http://www.isna.de/index2e.html on October 10, 2006.

Johnson M 1997 Women's health: Transcutaneous electrical nerve stimulation in pain relief. British Journal of Midwifery 5: 4000, 402-4-05.

Johnson M 2001 Transcutaneous electrical nerve stimulation (TENS) and TENS-like devices: Do they provide pain relief? Pain Reviews 8: 121-158.

Koehn M 2000 Alternative and complementary therapies for labour and birth: an application of Kolcaba's theory of holistic comfort. Holistic Nursing Practice 15: 66-77. 
Lancioni G, Singh N, O’Reilly M et al 2005 An overview of research on increasing indices of happiness of people with severe/profound intellectual and multiple disabilities. Disability and Rehabilitation 27: 83-93.

Lavender T, Walkinshaw S, Walton I 1999 A prospective study of women's views of factors contributing to a positive birth experience. Midwifery 15: 40-46.

McCaffrey R 2000 The lived experience of listening to music while recovering from surgery. Journal of Holistic Nursing 18: 378-390.

Mousley S 2005 Audit of an aromatherapy service in a maternity unit. Complementary Therapies in Clinical Practice 11: 205-210.

Nanayakkara S 2001 Complementary therapies in midwifery practice. In: McCabe P (ed) Complementary therapies in nursing and midwifery: from vision to practice. Ausmed Publications, Melbourne.

Ogden J, Shaw A, Zander L 1998 Women's experience of having a hospital birth. British Journal of Midwifery 6: 339-345.

Pinkney L 1997 A comparison of the Snoezelen environment and a music relaxation group on the mood and behaviour of patients with senile dementia. British Journal of Occupational Therapy 60: 209-12.

Polit D, Beck C 2006 Essentials of nursing research. 6th ed Lippincott, Philadephia.

Reddon J, Hoang T, Sehgal S et al. 2004 Immediate effects of Snoezelen treatment on adult psychiatric patients and community controls. Current Psychology 23: 225237.

Schofield P 1996 Snoezelen: Its potential for people with chronic back pain. Complementary Therapies in Nursing and Midwifery 2: 9-12.

Schofield P 2002 Specialist nursing: Evaluating Snoezelen for relaxation within chronic pain management. British Journal of Nursing 11: 814-21.

Schofield P, Davies B, Hutchinson R 1998 Evaluating the use of Snoezelen and chronic pain: The findings of an investigation into its use (part II). Complementary Therapies in Nursing and Midwifery 4: 137-43.

Schofield P, Payne S 2003 A pilot study into the use of a multisensory environment (Snoezelen) with a palliative day-care setting. International Journal of Palliative Nursing 9: 124-8.

Shilling T, DeFranco J, Simkin P et al 2004 Freedom of movement throughout labour. Journal of Perinatal Education 13: 11-15.

Simkin P, Bolding A 2004 Update on non-pharmacologic approaches to relieve labour pain and prevent suffering. Journal of Midwifery and Women's Health 49: 489504.

Smith C, Collins C, Cyna A et al 2003 Complementary and alternative therapies for pain management in labour. The Cochrane Database of Systematic Reviews, 2: CD003521.

Strauss A, Corbin J 1998 Basics of qualitative research. 2nd ed Sage, Newbury Park.

Tiran D 2003 Implementing complementary therapies into midwifery practice. Complementary Therapies in Nursing and Midwifery 9: 10-13.

Tiran D, Chummun H 2004 Complementary therapies to reduce physiological stress in pregnancy. Complementary Therapy in Nursing and Midwifery 10: 162-167.

van Diepen E, Baillon S, Redman J et al 2002 A pilot study of the physiological and behavioural effects of Snoezelen in dementia. British Journal of Occupational Therapy 65: 61-6. 
van Weert J, Kerkstra A, van Dulmen A et al 2004 The implementation of Snoezelen in psychogeriatric care: An evaluation through the eyes of caregivers. International Journal of Nursing Studies 41: 397-409.

Verkaik R, van Weert J, Francke A 2005 The effects of psychosocial methods on depressed, aggressive and apathetic behaviours of people with dementia: a systematic review. International Journal of Geriatric Psychiatry 20: 301-314.

White A 2003 Acupuncture reduced the need for conventional analgesics in labour. Focus on Alternative and Complementary Therapies 8: 48-49.

White J 1997 Creating a Snoezelen effect in PICU. Paediatric Nursing 9: 20-1. 
Figure 1 and 2
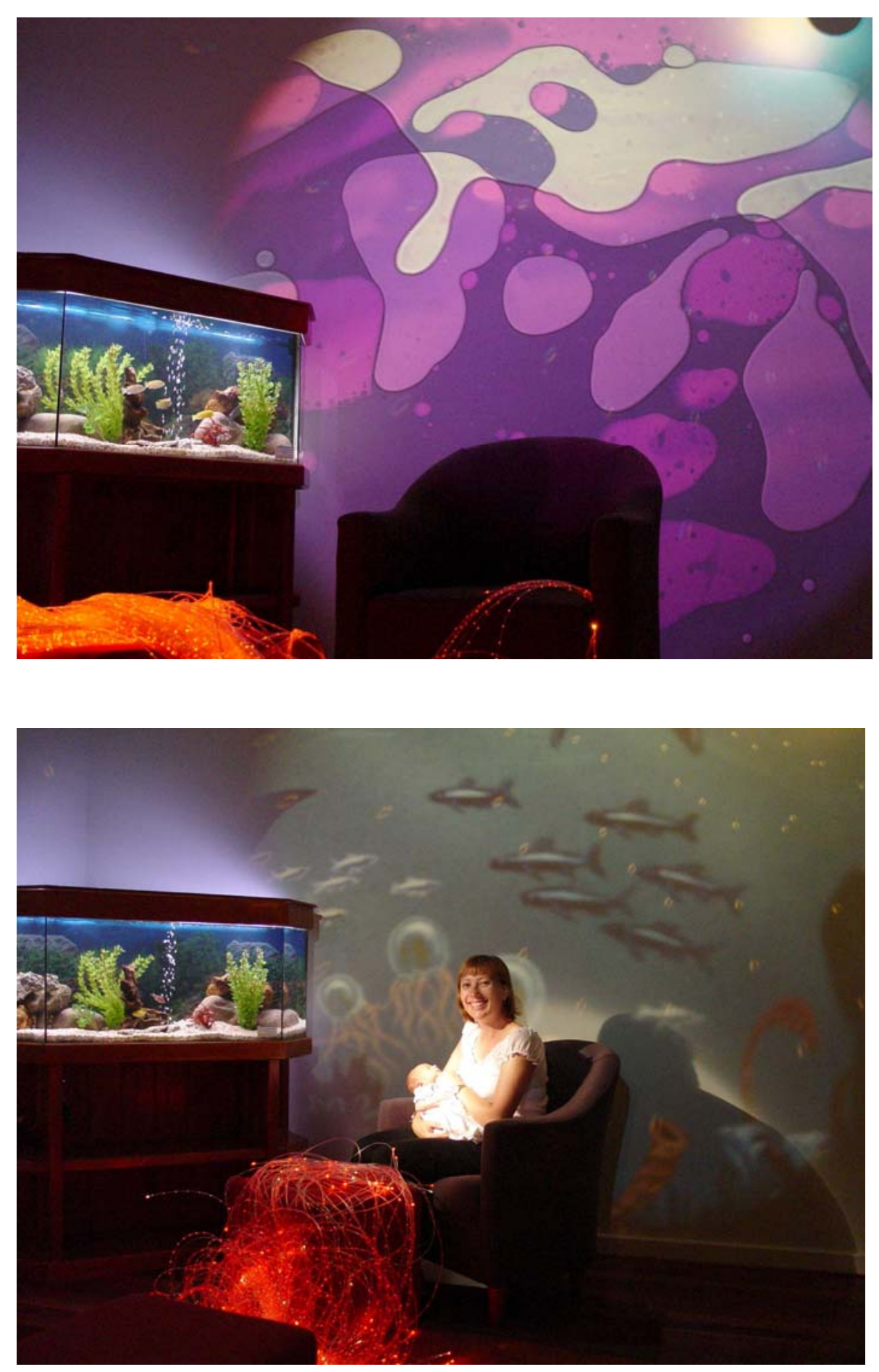
Safety in a non-clinical atmosphere
What a Snoezelen environment can offer to a labouring woman
Comfort

Environmental control

Choice of complementary therapy features

Figure 3. Snoezelen environment and the labouring woman: key themes

Box 1. Factors that facilitated or inhibited use of the Snoezelen environment

- Familiarity with features

- Information and choice

- Timing in labour

- Support person's response

- Working order of the room's features

Table 1 Demographic Profile

\begin{tabular}{|c|c|}
\hline Demographic Variable & Women $(n=16)$ \\
\hline \multicolumn{2}{|l|}{ Educational background } \\
\hline University & 9 \\
\hline Technical and further & 3 \\
\hline education & \\
\hline High school certificate & 2 \\
\hline $\begin{array}{l}\text { Completed year } 10 \text { in } \\
\text { high school }\end{array}$ & 2 \\
\hline \multicolumn{2}{|l|}{ Combined family income } \\
\hline$<\$ 29,000$ & 1 \\
\hline$\$ 30,000$ to $\$ 59,000$ & 7 \\
\hline$\$ 60,000$ to $\$ 79,000$ & 4 \\
\hline$>\$ 100,000$ & 3 \\
\hline \multicolumn{2}{|l|}{ Type of birth } \\
\hline Spontaneous vaginal birth & 7 \\
\hline $\begin{array}{l}\text { Instrumental birth (forcep } \\
\text { or vacuum) }\end{array}$ & 5 \\
\hline Caesarean birth & 4 \\
\hline
\end{tabular}

